\title{
physiospektrum
}

\section{Darf ich als Heilpraktikerin Therapierezepte ausstellen?}

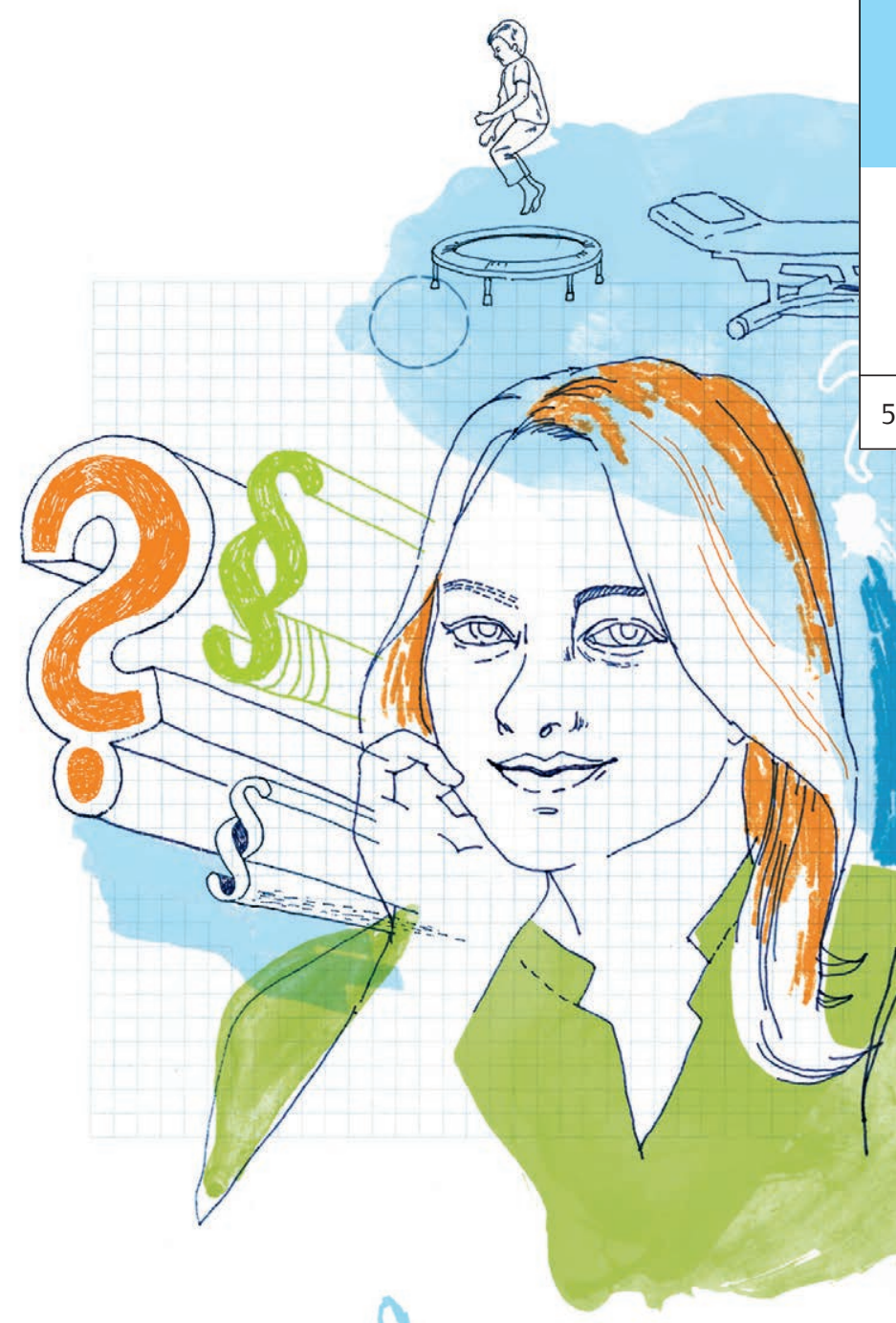

Die Rechtsfrage

„ Darf ich als sektorale Heilpraktikerin

Privatrezepte ausstellen, damit meine Physio-

therapie-Kollegen ihre Leistungen auf Privat-

rezept abrechnen können? Wenn ja, würde ja

sozusagen eine Heilpraktikerin ausreichen, um

die ganze Praxis mit Privatverordnungen zu

versorgen ... "

Susanne Ehrchen aus Hamburg

\section{Die Antwort unseres Experten}

Es gibt zahlreiche Therapiepraxen, die Heilpraktiker beschäftigen bzw. mit ihnen zusammenarbeiten. Jeder Heilpraktiker ist berechtigt, Heilmittel zu verordnen. Dies gilt - beschränkt auf den Bereich der Physiotherapie - auch für den sektoralen Heilpraktiker, also den Physio-Heilpraktiker. Für Ergotherapeuten gibt es keinen sektoralen Heilpraktiker. Allerdings können „vollständige“ Heilpraktiker selbstverständlich auch Verordnungen für Ergotherapie ausstellen.

Die Verordnung eines Heilpraktikers oder eines sektoralen Heilpraktikers ist notwendig, um zwei wichtige Effekte zu erzielen: Zum einen wird durch die Verordnung sichergestellt, dass der Therapeut bei der Behandlung nicht gegen das Heilpraktikergesetz verstößt und sich wegen unerlaubter Heilbehandlungen (außer im Fall von Massagen) strafbar macht. Zum anderen führt eine Verordnung durch einen (sektoralen) Heilpraktiker dazu, dass die Therapeuten für die jeweilige Leistung keine Umsatzsteuer abführen müssen unabhängig von der Kleinunternehmerregelung.

Im Gegensatz zur ärztlichen Verordnung berechtigt die Verordnung eines (sektoralen) Heilpraktikers nicht zur Abrechnung der Leistungen gegenüber der gesetzlichen Krankenversicherung. Ansonsten sind die Verordnungen von (sektoralen) Heilpraktikern und Ärzten in ihrer Wirkung identisch: Sie wahren die Vorschriften des Heilpraktikergesetzes, setzen sie um und schaffen die Voraussetzungen zur Umsatzsteuerfreiheit der späteren therapeutischen Leistung.

Damit vermuten Sie richtig: Es reicht ein (sektoraler) Heilpraktiker aus, um Verordnungen für eine oder mehrere Praxen auszustellen. Behandeln muss er anschließend nicht selbst, kann dies aber. Ob die jeweils aufgrund der Verordnung erbrachten Leistungen dann im Nachgang von der gesetzlichen oder einer privaten Krankenversicherung vergütet werden, ist allerdings eine Frage des Einzelfalls. Hier kommt es auf den Leistungskatalog der jeweiligen Kasse oder den Versicherungsvertrag an.

Philipp Groteloh

\section{$\Rightarrow$ Wirft auch Ihr Berufsalltag rechtliche Fragen auf? Dann schreiben Sie an Simone.Gritsch@thieme.de.}

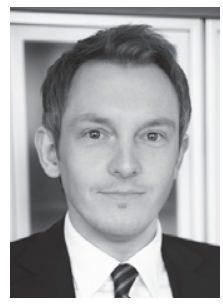

Dr. Philipp Groteloh ist seit 2007 Rechtsanwalt und seit 2012 Fachanwalt für Verwaltungsrecht. 